\title{
Optimal Design for Thrust Ripple Reduction of Stationary Distributed-Armature System
}

\author{
Eui-Jong Park ${ }^{1}$, Sang-Yong Jung ${ }^{2}$, Kyoung-Pil Cho ${ }^{1}$, and Yong-Jae Kim ${ }^{1 *}$ \\ ${ }^{1}$ Department of Electrical Engineering, Chosun University, Gwangiu 61452, Korea \\ ${ }^{2}$ School of Electronic and Electrical Engineering, Sungkyunkwan University, Suwon 16419, Korea
}

(Received 13 October 2015, Received in final form 1 December 2015, Accepted 18 December 2015)

\begin{abstract}
Although the initial cost of permanent-magnet linear synchronous motors is high owing to the installation of armatures over the full length of the transportation lines, linear motors are useful for transportation systems because of their high speed, acceleration, and deceleration. For these reasons, research into reducing the cost of linear motors is necessary, and a stationary distributed-armature system has been suggested for installing armatures in sections where acceleration and deceleration of the mover are required. However, each armature has ends that significantly increase the cogging force, resulting in the increase in the thrust ripple of the mover. Therefore, in order to improve the thrust ripple of the system, the present study aims to provide auxiliary teeth on both ends of the armature to achieve an optimal design through an analysis of the contribution ratio with respect to factors regarding the design of the experiment and the objective function.
\end{abstract}

Keywords : distributed-armature, end cogging force, auxiliary teeth, long-distance transportation

\section{Introduction}

Because the initial cost of permanent-magnet linear synchronous motors (PMLSMs) is high owing to the installation of armatures over the full length of the transportation lines, PMLSMs are not typically used in longdistance transportation systems despite their high thrust, precision, and high acceleration and deceleration $[1,2]$. A stationary distributed-armature (SDA) system has been suggested for installing armatures in sections where mover acceleration and deceleration are required to address the issue of the high initial cost of the PMLSM. However, in the SDA system, because it is essential to have one armature unit with a given number of slots arranged in transportation lines, each armature unit is inevitably structured to have armature ends. Such armature ends significantly increase the cogging force, resulting in an increase in the thrust ripple, which causes the mover to vibrate $[3,4]$.

In addition, when the mover passes the armature end, it means that the non-armature section is near. That is, the increasing thrust ripple in the non-armature section is

CThe Korean Magnetics Society. All rights reserved.

*Corresponding author: Tel: +82-62-230-7026

Fax:+82-62-230-7026, e-mail: kimyj21@chosun.ac.kr related to the stopping possibility of the mover.

Therefore, this study aims to determine the ideal armature shape to improve the thrust ripple and optimally design the proposed armature through an analysis of the contribution ratio with respect to factors regarding the design of the experiment and the objective function. For the analysis of the characteristics based on the armature shape, a 2D numerical-analysis program was used to determine the cogging force of each model using the finite-element method (FEM).

\section{Stationary Distributed-armature System}

\subsection{End cogging force of SDA system}

Figure 1 shows an SDA system and a continuousarmature system. The SDA system employs armatures only in the section where mover acceleration and deceleration are required, thereby minimizing the material costs and time required for manufacturing, depending on the distance between armatures. If armatures with a slot pitch of $40 \mathrm{~mm}$ are installed over $200 \mathrm{~m}$ of transportation lines, the continuous-armature system requires 5,000 slots. An SDA system, where each armature unit has 9 slots (360 $\mathrm{mm}$ ) and the interval between the armatures is $1 \mathrm{~m}$, requires 1,323 slots. If the interval between the armatures is $5 \mathrm{~m}, 342$ slots are required. This implies reductions in 


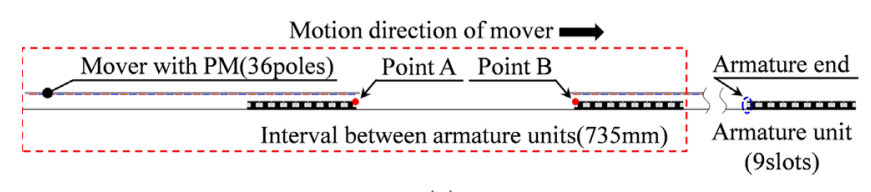

(a)

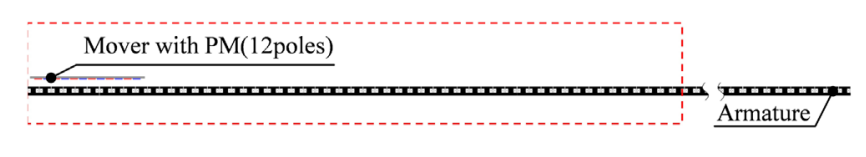

(b)

Fig. 1. (Color online) Armature arrangements: (a) distributed armature and (b) continuous armature.

the electrical steel sheets of $73.54 \%$ and $93.16 \%$, respectively, compared with those of the continuous-armature system. Table 1 describes the reduced electrical steel sheets with respect to the interval between the armatures.

Table 1 indicates that the SDA system is effective for reducing the material costs and time required for manufacturing. However, the structural characteristics of the SDA system give rise to an important issue: the armatures cause the cogging force to increase owing to the armature ends because the armatures are arranged discontinuously.

In general, a cogging force accelerates a mover if it is in the same direction as the mover's motion. If it is in the direction opposite to the mover's motion, it decelerates the mover. Such cogging forces occur because of the armature-teeth ends and the ends of the permanentmagnet teeth, which have a cycle. However, because the mover travels between armature units in the SDA system, it is essential to consider the cogging force due to both ends of the permanent magnet of the mover and the armature unit. This is called the "end cogging force." The waveform of the end cogging force for each pole with which the mover enters and exits the armature increases in a single direction and is irregular without periodicity.

The vibration and step out of the mover are increased by the end cogging force, which contributes to the force acting in the direction of the mover's motion, and accelerates the mover when it enters the armature [5]. A negative force acting in the direction opposite to the mover's motion decelerates the mover when it exits the armature. In addition, the increase in the thrust ripple in the non-armature section is related to the stopping possibility of the mover, as the armature end is a boundary between the armature section and non-armature section.

\subsection{Thrust characteristics of SDA PMLSM}

Table 2 shows the specifications and analysis information for the two systems. The mover of the SDA system comprises 36 poles, and that of the continuous-armature system comprises 12 poles. The reason for this composition is that the maximum number of effective poles for the mover to align one armature unit is 12 . Therefore, the 12-pole mover was used for the continuous-armature system to compare the two systems under the same conditions.

The dotted sections in Fig. 1 indicate the sections for analysis in the two systems. These are the sections in the SDA system from where the front end of the mover passes point $A$ to where the back end of the mover passes point B. There are 180,051 nodes and 343,926 elements in the numerical-analysis model.

Figure 2 shows the characteristics of the thrust force in

Table 1. Reduction ratio of used electrical steel sheet depending on armature interval.

\begin{tabular}{|c|c|c|c|}
\hline & $\begin{array}{l}\text { Number of arranged } \\
\text { armature units [Units] }\end{array}$ & $\begin{array}{c}\text { Number of arranged slots } \\
\text { [Slots] }\end{array}$ & $\begin{array}{c}\text { Reduction ratio of electrical } \\
\text { steel sheets [\%] }\end{array}$ \\
\hline Continuous-armature system & - & 5,000 & - \\
\hline $\begin{array}{l}\text { Discontinuous-armature system } \\
\quad \text { (armature interval: } 1 \mathrm{~m})\end{array}$ & 147 & 1,323 & 73.54 \\
\hline $\begin{array}{l}\text { Discontinuous-armature system } \\
\quad \text { (armature interval: } 5 \mathrm{~m})\end{array}$ & 38 & 342 & 93.16 \\
\hline
\end{tabular}

Table 2. Analysis information and specification with respect to armature-arrangement method.

\begin{tabular}{ccc}
\hline & Distributed armature & Continuous armature \\
\hline Number of mover magnets (length) & 36 poles $(1,080 \mathrm{~mm})$ & 12 poles $(360 \mathrm{~mm})$ \\
Number of one unit armature slots (length) & 9 slots $(360 \mathrm{~mm})$ & - \\
Interval between armature units & $735 \mathrm{~mm}$ & $1,815 \mathrm{~mm}$ \\
Analysis section & & $265 \mathrm{AT}$ \\
Magnetomotive force & $16.67 \mathrm{~Hz}$ \\
Frequency & & \\
\hline
\end{tabular}




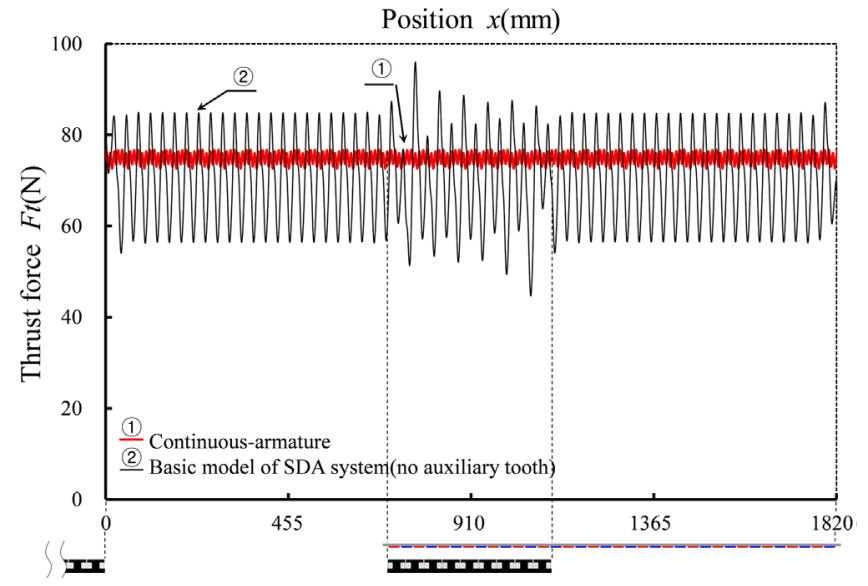

Fig. 2. (Color online) Thrust-force comparison between continuous and discontinuous armatures.

the SDA system and the continuous-armature system. The numerical analysis indicated that the average thrust forces were $70.32 \mathrm{~N}$ and $74.80 \mathrm{~N}$ for the SDA and continuousarmature systems, respectively. Hence, there is a small difference of $5.98 \%$ in the average thrust force. Although the thrust ripple of the continuous-armature system was $5.52 \%$, that of the SDA system was $40.74 \%$, which is greater. Such an increase in the thrust ripple is attributed to the significantly increased cogging force caused by the armature ends, that is, the end cogging force arising from the structure of the SDA system. Therefore, it is necessary to reduce the end cogging force to improve the thrust ripple.

\section{Thrust-ripple Improvement Using Auxiliary Teeth}

\subsection{Method for reducing end cogging force}

Generally, it is possible to reduce the detent force that degrades the performance of equipment using one of the following methods: bifurcation and chamfering, which affect the shape of the armature teeth; the auxiliary-pole method, which affects the magnetic circuit of the permanent magnet; and the auxiliary-teeth method, which

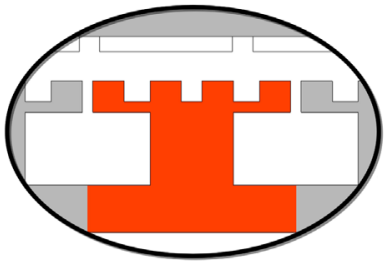

(a)

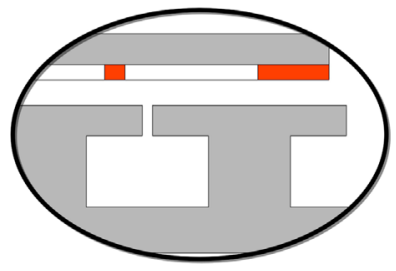

(c)

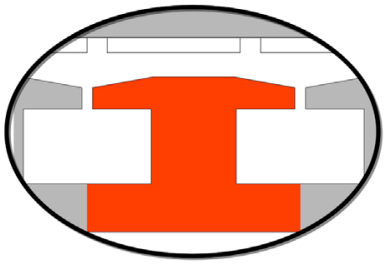

(b)

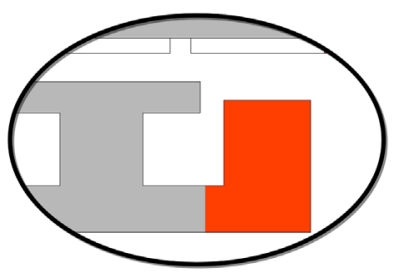

(d)
Fig. 3. (Color online) Detent-force reduction methods: (a) Teeth bifurcation, (b) Teeth chamfering, (c) Auxiliary pole, and (d) Auxiliary teeth.

affects the magnetic flux of the armature end. However, because the thrust may also be reduced by these processes, careful consideration is required. Various methods were attempted to reduce the detent force, as shown in Fig. 3 [6-9]. They are summarized in Table 3, which shows that bifurcation and chamfering are very effective for reducing the detent force caused by the teeth. However, because the force that greatly affects the mover in the proposed discontinuously arranged armature system is the end detent force, these methods are not suitable. Moreover, these methods increase the air gap and change the magnetic circuit, thus decreasing the flux density in the air gap, which adversely affects the back electromotive force and thrust. On the other hand, auxiliary teeth are optimal for reducing the end cogging force.

Therefore, in this study, the installation of auxiliary teeth at both ends of the armature unit is proposed to reduce the end cogging force.

\subsection{Design of experiment}

An orthogonal array was employed for optimal design of the auxiliary tooth. Figure 4 shows $\mathrm{X}, \mathrm{Y}$, and D as

Table 3. Characteristics of each detent-force-reduction method.

\begin{tabular}{|c|c|c|c|c|c|c|}
\hline & Reduction methods & $\begin{array}{l}\text { Reduction of teeth } \\
\text { Fd }\end{array}$ & $\begin{array}{l}\text { Reduction of } \\
\text { end Fd }\end{array}$ & $\begin{array}{l}\text { Back } \\
\text { EMF }\end{array}$ & Thrust & Parameters \\
\hline (a) & Teeth Bifurcation & (2) & $\triangle$ & $x$ & $x$ & 3 \\
\hline (b) & Teeth Chamfering & (0) & $\triangle$ & $\triangle$ & $\triangle$ & 2 \\
\hline (c) & Auxiliary Pole & 0 & $\triangle$ & 0 & 0 & 3 \\
\hline (d) & Auxiliary Teeth & $x$ & O & (0) & () & 6 \\
\hline
\end{tabular}




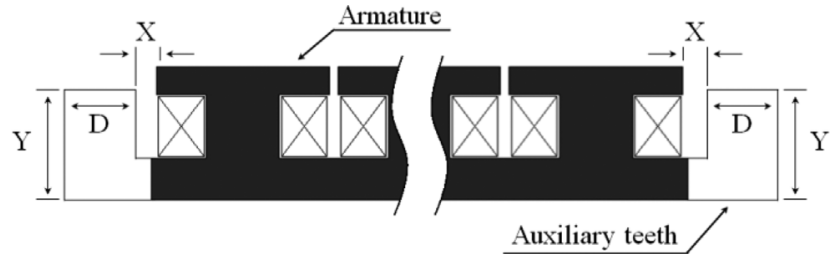

Fig. 4. Auxiliary-teeth model.

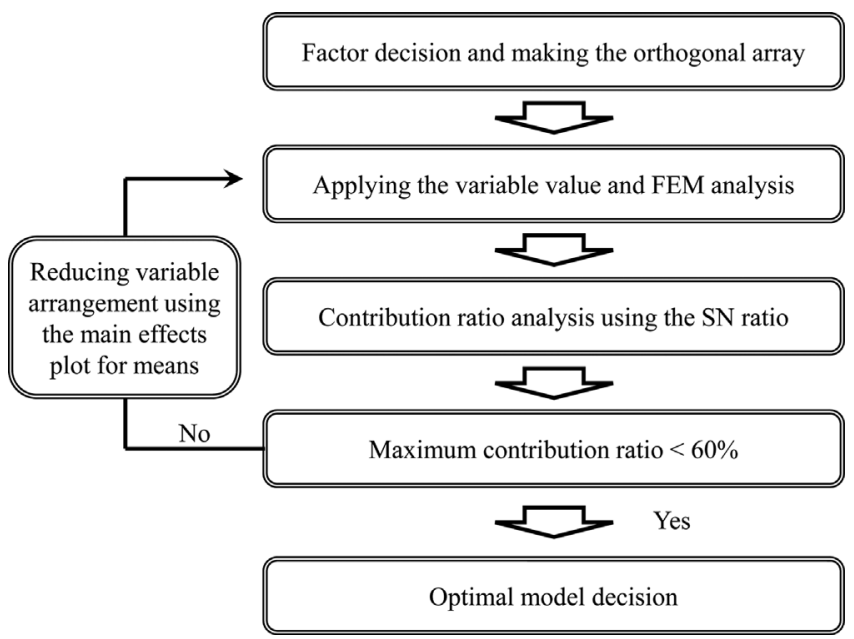

Fig. 5. Procedure of the optimal design.

factors that comprise the orthogonal array. The factors were composed of level 3, depending on the maximum and the minimum of each factor. Among the signal-tonoise (SN) ratios used to effectively estimate the effect of the noise factors on the process characteristics, thesmaller-the-better characteristic SN ratios-which correspond to the minimum of the objective function- were used to analyze the contribution ratio of each factor to the changes in the end-cogging-force magnitude [10-13]. A greater contribution ratio indicates a greater change in the objective function as the level of the factor changes. Therefore, the analysis was repeated to reduce the scope of the factor levels in order to obtain an ideal contribution ratio for a new orthogonal array, and then the contribution ratio was analyzed again. "The analysis is repeated until one factor's contribution ratio is less than twice of the other factor to relieve unequal distribution of the contribution ratio. In this paper, the standard limit is $60 \%$. Figure 5 shows the procedure for the optimal design. The $\mathrm{SN}$ ratio is represented as (1):

$$
\mathrm{SN} \text { ratio }=-10 \log _{10} \Sigma \frac{y^{2}}{n}
$$

where $y$ is the end detent force obtained from the analysis and $n$ is the number of repetitions of the analysis.

The maximum end cogging force, orthogonal array for
Table 4. First orthogonal array.

\begin{tabular}{cccccc}
\hline \hline & $\mathrm{X}$ & $\mathrm{Y}$ & $\mathrm{D}$ & $\begin{array}{c}\text { End cogging } \\
\text { force }\end{array}$ & SN ratio \\
\hline 1 & $1[\mathrm{~mm}]$ & $20[\mathrm{~mm}]$ & $40[\mathrm{~mm}]$ & $27.22[\mathrm{~N}]$ & -28.6990 \\
2 & $1[\mathrm{~mm}]$ & $13[\mathrm{~mm}]$ & $27[\mathrm{~mm}]$ & $14.98[\mathrm{~N}]$ & -23.5079 \\
3 & $1[\mathrm{~mm}]$ & $6[\mathrm{~mm}]$ & $14[\mathrm{~mm}]$ & $23.53[\mathrm{~N}]$ & -27.4308 \\
4 & $2[\mathrm{~mm}]$ & $20[\mathrm{~mm}]$ & $27[\mathrm{~mm}]$ & $31.66[\mathrm{~N}]$ & -30.0101 \\
5 & $2[\mathrm{~mm}]$ & $13[\mathrm{~mm}]$ & $14[\mathrm{~mm}]$ & $6.33[\mathrm{~N}]$ & -16.0294 \\
6 & $2[\mathrm{~mm}]$ & $6[\mathrm{~mm}]$ & $40[\mathrm{~mm}]$ & $26.17[\mathrm{~N}]$ & -28.3571 \\
7 & $3[\mathrm{~mm}]$ & $20[\mathrm{~mm}]$ & $14[\mathrm{~mm}]$ & $35.90[\mathrm{~N}]$ & -31.1014 \\
8 & $3[\mathrm{~mm}]$ & $13[\mathrm{~mm}]$ & $40[\mathrm{~mm}]$ & $18.69[\mathrm{~N}]$ & -25.4335 \\
9 & $3[\mathrm{~mm}]$ & $6[\mathrm{~mm}]$ & $27[\mathrm{~mm}]$ & $25.41[\mathrm{~N}]$ & -28.1004 \\
\hline
\end{tabular}

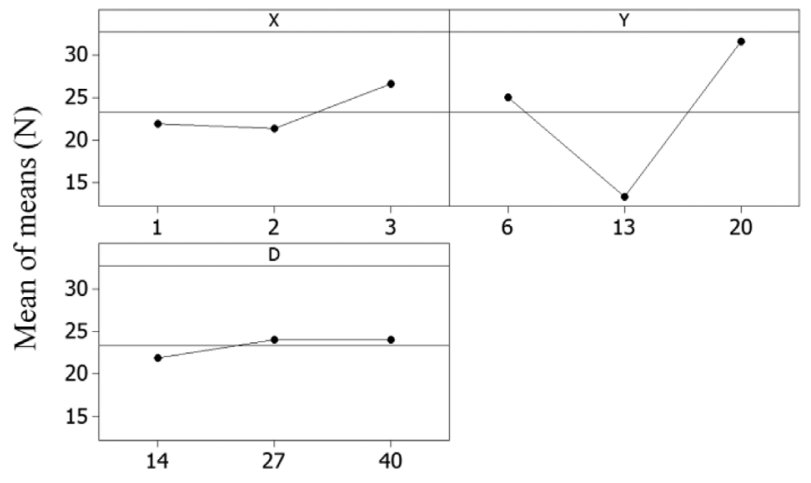

Fig. 6. First main effects plot for means.

the optimal design of the auxiliary teeth, and SN ratio are listed in Table 4. Figure 6 shows plots of the main effects of the means that illustrate the effect of each factor related to the end cogging force. Before the contribution ratio is calculated, the average end cogging force for the models using the same levels should be calculated. In this experimental design, as shown in Table 5, 9 average values can be derived, as 3 factors and 3 levels are used. The sum of squares can be calculated using the average values, and the contribution ratio can be derived as a percentage of the sum of squares. The most influential factor is Y, with a contribution ratio of $78.86 \%$, and as shown in Fig. 6, the $Y$ varies extensively. In addition, the maximum end cogging force for $\mathrm{Y}$ is low before and after level 13. Therefore, the orthogonal array should be rewritten because

Table 5. First contribution ratio.

\begin{tabular}{ccccc}
\hline \hline & $\mathrm{X}$ & $\mathrm{Y}$ & $\mathrm{D}$ & Sum \\
\hline Level 1 & -26.55 & -29.94 & -27.50 & \\
Level 2 & -24.80 & -21.66 & -27.21 & -238.67 \\
Level 3 & -28.21 & -27.96 & -24.85 & \\
Sum of squares & 1.94 & 12.47 & 1.40 & 15.81 \\
Contribution ratio [\%] & 12.28 & 78.86 & 8.86 & 100 \\
\hline
\end{tabular}


Table 6. Average end cogging force and contribution rate with respect to orthogonal array.

\begin{tabular}{cccc}
\hline \hline & First orthogonal array table & Second orthogonal array table & Third orthogonal array table \\
\hline $\begin{array}{c}\text { Maximum contribution factor } \\
\text { (Contribution ratio) }\end{array}$ & Factor Y & Factor D & Factor X \\
$\begin{array}{c}\text { Average end cogging force of the } \\
\text { orthogonal array table }\end{array}$ & $(78.86 \%)$ & $(59.64 \%)$ & $(56.31 \%)$ \\
& $23.32 \mathrm{~N}$ & $16.98 \mathrm{~N}$ & $12.94 \mathrm{~N}$ \\
\hline
\end{tabular}

the contribution ratio is more than $60 \%$. The modified orthogonal array for $\mathrm{Y}$ has levels of 10,13, and 16. The same analysis process was repeated thrice, and Table 6 illustrates the contribution ratios with respect to the repetitions, as well as the changes in the average end cogging force in the orthogonal array.

\subsection{Discussion of the result}

As shown in Table 6, the level required to minimize the end cogging force is determined by reducing the level range of the factor with the greatest contribution ratio. This process can be used to develop an optimal model in order to minimize the end cogging force. The effect of the reduced average cogging force on the orthogonal array following the repetition of the process shown in Table 6 indicates that the optimal model can be obtained with such a method.

In this study, the optimal auxiliary tooth $(X=1 \mathrm{~mm}$, $\mathrm{Y}=13 \mathrm{~mm}, \mathrm{D}=18 \mathrm{~mm}$ ), which was determined from experiments, was applied to the SDA system, and numerical analysis was performed under the analysis conditions suggested in Section 2. Figure 7 shows the thrust-force waveform of the model to which the numerically analyzed auxiliary tooth was applied. As shown in Figure 7, the auxiliary tooth installed on both ends of the armature contributed to an average thrust force of $72.38 \mathrm{~N}$ and thrust ripple of $16.25 \%$, increasing the average thrust force by $2.85 \%$ and decreasing the thrust ripple by $60.11 \%$

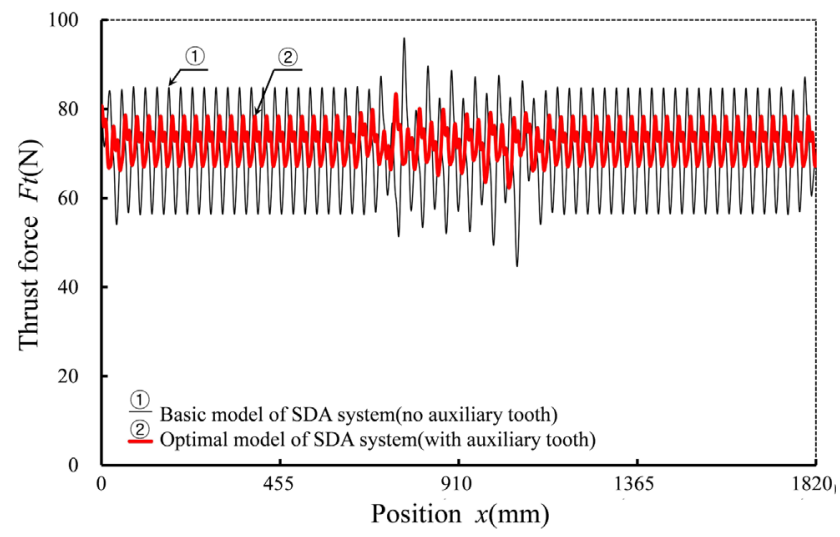

Fig. 7. (Color online) Thrust-force comparison between continuous and distributed armatures with auxiliary teeth. compared with those of the model without auxiliary teeth.

\section{Conclusion}

This study aimed at reducing end cogging force by installing auxiliary teeth at both ends of an armature unit with an optimal design in order to reduce the thrust-ripple increase for the armature ends of the distributed-armature system. The average thrust force of the ideal model was $72.38 \mathrm{~N}$ and the thrust ripple was $16.25 \%$. This represents an increase of $2.85 \%$ in the average thrust force and a decrease of $60.11 \%$ in the thrust ripple from those of the model without auxiliary teeth. The proposed method improved the thrust ripple by reducing the end cogging force of the distributed-armature system. The thrust characteristics of the continuous-armature system were compared with those of the distributed-armature system to which the auxiliary teeth were applied in order to confirm the usability of the distributed-armature system. This comparison revealed that the average thrust force of the distributed-armature system to which the auxiliary teeth was applied was reduced by $3.34 \%$, which is not a significant change. The thrust-ripple comparison revealed a $10.73 \%$ change, which is also insignificant. Therefore, we conclude that the distributed-armature system with auxiliary teeth is more economical and ideal for transportation systems, considering the low installation costs.

\section{Acknowledgements}

This work was supported by the Human Resource Training Program for Regional Innovation and Creativity through the Ministry of Education and National Research Foundation of Korea (NRF-2014H1C1A1066713).

\section{References}

[1] K. C. Lim, J. K. Woo, G. H. Kang, J. P. Hong, and G. T. Kim, IEEE Trans. Magn. 38, 2 (2002).

[2] J. Y. Lee, J. W. Kim, B. H. Woo, and D. H. Kang, J. Magn. 18, 2 (2013).

[3] D. W. Chung and Y. M. You, J. Magn. 20, 2 (2015).

[4] Y. U. Park, J. H. Cho, S. H. Rhyu, and D. K. Kim, J. 
Magn. 18, 2 (2013).

[5] I. S. Hwang, H. S. Yoon, and C. S. Koh, Trans. KIEE. 57, 4 (2008).

[6] Y. J. Kim, K. M. Lee, and M. Watada, J. Magn. 16, 3 (2011).

[7] C. F. Wang, J. X. Shen, Y. Wang, L. L. Wang, and M. J. Jin, IEEE Trans. Magn. 45, 6 (2009).

[8] C. C. Hwang, P. L. Li, and C. T. Liu, IEEE Trans. Magn. 48, 2 (2012).
[9] Y. J. Kim, J. The Korea Institute of Electronic Communication Sciences 7, 5 (2012).

[10] D. H. Hyun and Y. S. Lee, J. of the Korea Soc. of Automotive Engineers 14, 6 (1992).

[11] A. M. Omekanda, IEEE Trans. Ind. Appl. 42, 2 (2006).

[12] S. Brisset, F. Gillon, S. Vivier, and P. Brochet, IEEE Trans. Magn. 37, 5 (2001).

[13] Y. H. Liu, C. H. Hsieh, and Y. F. Luo, IEEE Trans. Energy Conversion 26, 2 (1999). 